\title{
Uniaxial tensile behavior of aligned steel fibre reinforced cementitious composites
}

\author{
Longbang Qing $\cdot$ Kelai Yu $\cdot$ Ru Mu $\cdot$ John P. Forth
}

Received: 20 January 2019/ Accepted: 20 June 2019/Published online: 25 June 2019

(C) The Author(s) 2020, corrected publication 2020

\begin{abstract}
By applying an external uniform magnetic field to a fresh cement mixture during casting, an aligned steel fibre reinforced cementitious composites (ASFRC) was prepared. This investigation compares the performance of ASFRC with its counterpartordinary steel fibre reinforced cementitious composite (SFRC) containing randomly distributed steel fibres. First, the orientation of the steel fibres in ASFRC and SFRC specimens was examined using X-ray computed tomography analysis; this confirmed that the steel fibres were effectively aligned in the ASFRC. Then, uniaxial tensile tests were performed to allow a comparison of the uniaxial tensile stress-strain curves of the ASFRC and SFRC; and to determine the advantages, if any of ASFRC over SFRC in terms of uniaxial tensile strength $\left(f_{\mathrm{Utu}}\right)$, ultimate strain $\left(\varepsilon_{\mathrm{Utu}}\right)$ and energy dissipation $\left(G_{f-A}\right)$. The uniaxial tensile test results were also used to show that, if the tensile
\end{abstract}

Electronic supplementary material The online version of this article (https://doi.org/10.1617/s11527-019-1374-5) contains supplementary material, which is available to authorized users.

L. Qing $\cdot$ K. Yu $\cdot$ R. Mu $(\bowtie)$

School of Civil and Transportation Engineering, Hebei

University of Technology, 5340 Xiping Road,

Tianjin 300401, China

e-mail: ru_mu@hotmail.com

J. P. Forth

School of Civil Engineering, University of Leeds, Leeds, UK strength of ASFRC is equal to that of SFRC (actually slightly exceeding) using the aligned steel fibre technology, the dosage of steel fibres can be reduced at least $40 \%$. It was also found that the alignment of the steel fibres affects the strain-hardening and multiple cracking behavior of the composites during uniaxial tension testing. Finally, the multiple cracking behavior of the composites was analyzed using a digital image correlation method. These results show that ASFRC exhibits a multiple cracking pattern at a much lower fibre content compared to SFRC.

Keywords Steel fibre reinforced cementitious composites - Aligned steel fibre - Uniaxial tensile strength $\cdot$ Strain-hardening $\cdot$ Multiple cracking

\section{Introduction}

By incorporating steel fibres into the cement mortar matrix, the tensile strength, cracking resistance, impact and fatigue resistance of cementitious composites can be effectively enhanced [1-8]. Hence, steel fibres are usually added into concrete to improve its ductile behavior. However, in recent years, most experimental studies [1-8] focussed on SFRC with randomly dispersed fibres, and the theoretical value of fibre orientation number for dispersed steel fibres in an ordinary SFRC specimen is 0.405 [9]. As in some structural elements (beam, slab, tunnel segment, etc.) 
in service the direction of the principal stress is constant, the orientation of most steel fibres is therefore not consistent with the direction of the tensile stress during the loading process, and only a part of the fibres act effectively as reinforcement. It has been demonstrated that the orientation and distribution of fibres have a significant influence on the mechanical behavior of SFRC [10-13]. Obviously, if the orientation of steel fibres can be aligned with the direction of the principal tensile stress of the structural members, the tensile behavior and ductility of the SFRC structural members will be improved significantly.

Several methods have been reported to control the orientation of steel fibres in cementitious composites. A centrifugal casting technology has been used to prepare aligned steel fibre reinforced concrete poles by Rotondo et al. [14]. A special machine was used to spray steel fibres so that the steel fibres were aligned to the specific axis direction of the structural element [15]. By pouring fresh self-compacting concrete mixed with steel fibres through a chute [16] or a U-shape channel $[17,18]$, the steel fibres tend to be oriented parallel to the flow direction of the matrix. Specimens with different fibre orientations can be obtained by cutting the matrix in different directions, e.g., direction that is parallel or perpendicular to the concrete flow direction. Duque et al. [16] and Abrishambaf et al. [17, 18] assessed the influence of fibre orientation on the post-cracking behavior for steel fibre reinforced self-compacting concrete panels (SFRSCC). A U-shape iron core around a copper wire coil was used to align fibres while casting ultra-high performance fibre reinforced cementitious composites (UHPFRC) specimens by Nunes et al. [19, 20], the advantage of this set up is that the specimens can be prepared without the influence of the element shape [19-21]. Recently, Abrishambaf et al. [22] used a similar device $[19,20]$ to prepare UHPFRC specimens, and the uniaxial tensile test was used to study the influence of fibre orientation on the tensile behavior of UHPFRC. Both the straight smooth fibres and the hooked-end fibres were aligned by placing the sample in an electromagnetic field, formed by a spiral coil; the orientation of fibres was revealed by X-ray images [23]. The deflection of specimens in bending was detected using a digital image correlation (DIC) method as proposed by Michels et al. [23] who also studied the effect of fibre orientation on the flexural behavior. Likewise, Mu et al. [24, 25] and Wijffels et al. [26] analyzed the effects of the magnetic field distribution and the time of magnetization on the fibre alignment based on the principles of electromagnetics, respectively. The ASFRC specimens were prepared by a uniform magnetic field, which was formed using energized coils during casting [24, 25]. The X-ray computed tomography (CT) results of ASFRC specimens showed that the fibre orientation number can exceed $0.9(w / c=0.42)$ [24], and the results of splitting, flexural and shear strength tests [24, 25] showed that the mechanical performance of ASFRC specimens was evidently superior to SFRC specimens; the reinforcement efficiency of steel fibres was significantly improved by aligning fibres utilizing a magnetic field.

The cracking resistance of SFRC has an important influence on its practical application in engineering, and tensile strength is often used for evaluating cracks in structural members. A uniaxial tensile test is the most reliable and direct method to obtain tensile strength and to study the cracking behavior of SFRC. Moreover, compared to the splitting and flexural tests, the uniaxial tensile test was used to assess the nonlinear fibre-matrix interfacial response on the post-peak ductile behavior of SPRC [27]. Therefore, the uniaxial tensile test was applied to effectively study the tensile behavior of ASFRC, and contribute to its practical application.

The fibre volume fraction $\left(V_{\mathrm{f}}\right)$ and matrix strength have a remarkable effect on the mechanical behavior of the SFRC specimens. With the increase of fibre content or matrix strength, tensile strength and toughness can be significantly improved [28-30], the multiple cracking and strain-hardening behavior in the post-cracking stage under uniaxial tension [31-36] can be observed. In addition, the orientation of fibres also affects mechanical properties, multiple cracking and strain-hardening were obtained with specimens with sectional dimensions of $30 \mathrm{~mm} \times 40 \mathrm{~mm}$ using a griping system [22], and the test results showed that the tensile strength and post-peak toughness can be significantly enhanced by aligning the fibres. However, the effects of fibre content $\left(V_{\mathrm{f}}\right)$ and water to cement ratio $(w / c)$ on the tensile behavior of ASFRC specimens were not clear. Furthermore, the strainhardening characteristics and the evolution of fracture for ASFRC specimens under uniaxial tension as well as affecting other factors are not clarified. Generally, 
the orientation of fibres will be greatly affected by boundary effects $[37,38]$ if the size of specimen is relatively small, and the tensile strength obtained (often overestimated) is not comparable with the behavior of the structure. So, to facilitate the engineering application of ASFRC, uniaxial tensile tests should be carried out with specimens having relatively larger dimensions.

The aim of this investigation is to study the effect of fibre orientation on the strain-hardening and multiple cracking behavior of steel fibre reinforced cementitious composites in order to better exploit the high performance of cementitious composite materials. Prismatic specimens were prepared, and then uniaxial tensile tests were carried out with SFRC and ASFRC specimens with different fibre volume fractions and matrix strengths. Subsequently, the influence of fibre orientation on the strain-hardening behavior and fracture properties of such composites was studied. Under uniaxial tensile loads, the evolution of fracture for ASFRC specimens was revealed using the DIC method.

\section{Experimental programme}

\subsection{Test set-up}

Uniaxial tensile tests were carried out using a servohydraulic closed loop testing machine with a tensile capacity of $1000 \mathrm{kN}$ as shown in Fig. 1 (the actual

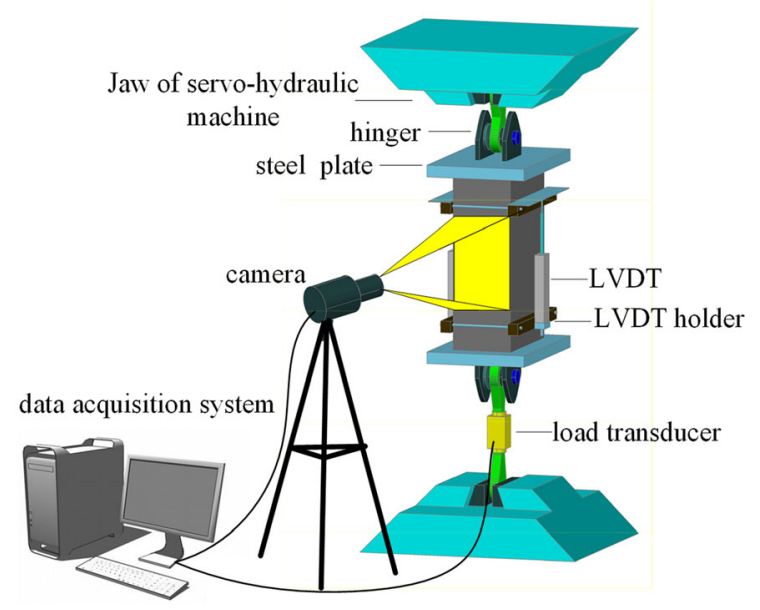

Fig. 1 Experimental device for the DIC and uniaxial tensile system loading configuration can be seen in Fig. S1 in the Supplementary Material). To load the specimen, a steel plate with a spherical hinge was first glued to each end of the specimen using epoxy resin (the curing cycle of the epoxy resin is a bit longer than $24 \mathrm{~h}$ ); the specimen was then connected to the loading machine via the spherical hinge-this effectively eliminated any applied load eccentricity (similar to the test set-up of Ding et al. [30]). In order to further ensure that the application of the load was concentric, the ends of the specimens were squared off before the steel plates were attached. Two linear variable differential transformers (LVDTs) were fixed on short wooden strips which were installed at the two opposite side surfaces of the specimen, the LVDTs can measure the elongation of the specimen (as shown in Fig. 1). The DIC system was also installed to test full field strain, which can be used to identify the initial cracking and the progressive cracking process until the complete failure of a specimen under uniaxial tension. As it is a noncontact test with full field measurement, the DIC system can precisely monitor the development of cracks [39]. The loading procedure consisted of two stages: the first stage was stress controlled-the loading rate was $0.4 \mathrm{MPa} / \mathrm{min}$ and the load was increased to about $80 \%$ of $P_{\max }$ (peak load) and this was followed by the second stage which was displacement controlled-here, the loading rate was $0.1 \mathrm{~mm} /$ min. The specimens were tested 28 days after casting.

\subsection{Mixes and specimen preparation}

Several groups of prism specimens with dimensions of $100 \mathrm{~mm} \times 100 \mathrm{~mm} \times 400 \mathrm{~mm}$ were cast. The ends of the specimen were ground parallel with a machine such that the actual height of the specimens was $300 \mathrm{~mm}$ after cutting. Straight smooth steel fibres with a diameter of $0.50 \mathrm{~mm}$ and a length of $30 \mathrm{~mm}$ were used in the mortar matrix. The Ordinary Portland Cement (OPC) of grade P.O 42.5 and silica sand with a fineness modulus of 2.6 were used to prepare the mortar investigated in this study. In order to facilitate the alignment of the steel fibres, the coarse aggregates were excluded, and polycarboxylate superplasticizer was added to the water to ensure that the mortar had sufficient fluidity and an excellent workability. The procedure for mixing different mortar mixes and the details of preparing ASFRC were previously described in a publication [24]. During the preparation of 
ASFRC specimens, the steel fibres and fresh mortar were mixed evenly and poured into plastic moulds, which were placed on the vibrating table with a uniform magnetic field device (basically, it is a square solenoid coil looped around a hollow chamber, which creates a uniform magnetic chamber in which the ASFRC specimens were placed). During vibration, steel fibres in the fresh mixture rotated in the direction of the magnetic field produced by the electromagnetic field. In this study, SFRC specimens $\left(V_{\mathrm{f}}=2.0 \%\right)$ with a water to cement ratio of $0.42,0.36$ and 0.32 were prepared (six types of mixtures are presented in Table 1); three specimens for each mix proportion were cast.

\section{Orientation of aligned fibres in ASFRC and SFRC}

The orientation of the steel fibres in the mortar samples was first visually investigated by examining the cracked section of the specimens after the tensile tests, the failed specimens are shown in Fig. S2 in the Supplementary Material. As expected, it can be identified from the cracked ASFRC specimens that most of the steel fibres were oriented parallel to the direction of the principal stress. Also note, that more steel fibres cross the cracked section of ASFRC specimens compared to SFRC specimens (the average number of fibres of ASFRC specimens $N_{f-A}$ with $V_{\mathrm{f}}=0.8 \%, 1.2 \%$ and $2.0 \%$ was 239,337 and 612 , respectively; the average number of fibres of SFRC specimens $N_{f-R}$ with $V_{\mathrm{f}}=0.8 \%, 1.2 \%$ and $2.0 \%$ was 193, 271 and 495, respectively). The orientation of the steel fibres in the specimens can also be directly observed once the failed specimens were separated into their two parts, as shown in Fig. 2. The steel fibres within the cracked section of the ASFRC specimen are effectively aligned parallel to the direction of the principal tensile stress, whilst those in the cross section of the SFRC specimen were randomly oriented. Besides visually comparing the differences in orientation of steel fibres in the ASFRC and SFRC specimens, X-ray CT tests were also performed. The $\mathrm{X}$-ray CT test is non-destructive and a three-dimensional assessment; the fibre orientation number can be determined from the X-ray CT analysis, as described by $\mathrm{Mu}$ et al. [24]. Figure 3 shows typical X-ray CT results of the ASFRC and SFRC specimens. The orientation numbers of ASFRC specimens $\left(V_{\mathrm{f}-}\right.$ $=2.0 \%)$ with $w / c=0.42,0.36$ and 0.32 were 0.90 , 0.87 and 0.88 , respectively. The orientation numbers of SFRC specimens $\left(V_{\mathrm{f}}=2.0 \%\right)$ with $w / c=0.42,0.36$ and 0.32 were $0.48,0.49$ and 0.51 , respectively. The orientation numbers of ASFRC and SFRC specimens $(w / c=0.36)$ with $V_{\mathrm{f}}=0.8$ were 0.92 and 0.56 , respectively, with a fibre dosage of $V_{\mathrm{f}}=1.2 \%$ they were 0.90 and 0.52 , respectively. Therefore, the fibre orientation number was about 0.90 in the ASFRC specimen, while it was about 0.50 in the SFRC specimen.

\section{Results}

The effects of fibre orientation on the uniaxial tensile stress-strain curves, tensile parameters and multiple cracking behavior were quantitatively analyzed for the experimental test results of SFRC and ASFRC.

Table 1 Mix proportion of cement mortars

\begin{tabular}{llllllll}
\hline $\begin{array}{l}\text { Mix } \\
\text { number }\end{array}$ & $\begin{array}{l}\text { Water to cement } \\
\text { ratio }(w / c)\end{array}$ & $\begin{array}{l}\text { Fibre volume fractions } \\
\left(V_{\mathrm{f}}\right)(\%)\end{array}$ & $\begin{array}{l}\text { Fibre }(\mathrm{kg} / \\
\left.\mathrm{m}^{3}\right)\end{array}$ & $\begin{array}{l}\text { Water }(\mathrm{kg} / \\
\left.\mathrm{m}^{3}\right)\end{array}$ & $\begin{array}{l}\text { Cement } \\
\left(\mathrm{kg} / \mathrm{m}^{3}\right)\end{array}$ & $\begin{array}{l}\text { Sand }(\mathrm{kg} / \\
\left.\mathrm{m}^{3}\right)\end{array}$ & $\begin{array}{l}\text { Superplasticizer } \\
\left(\mathrm{kg} / \mathrm{m}^{3}\right)\end{array}$ \\
\hline 1 & 0.42 & 2.0 & 156.0 & 269 & 639 & 1279 & 0.0 \\
2 & 0.36 & 0.8 & 62.4 & 239 & 664 & 1329 & 3.984 \\
3 & 0.36 & 1.2 & 93.6 & 239 & 664 & 1329 & 3.984 \\
4 & 0.36 & 1.6 & 124.8 & 239 & 664 & 1329 & 3.984 \\
5 & 0.36 & 2.0 & 156.0 & 239 & 664 & 1329 & 3.984 \\
6 & 0.32 & 2.0 & 156.0 & 220 & 689 & 1377 & 6.890 \\
\hline
\end{tabular}



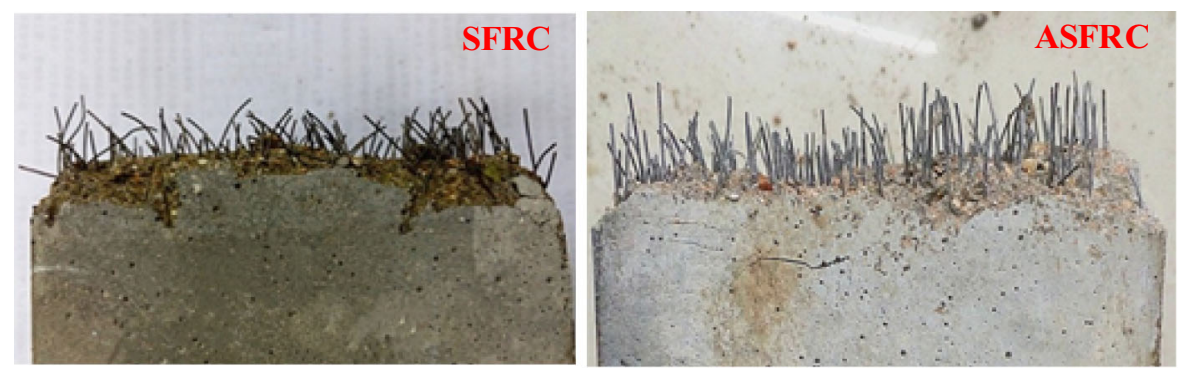

Fig. 2 Failed cross sections of specimens with $w / c=0.36$ and $V_{\mathrm{f}}=2.0 \%$
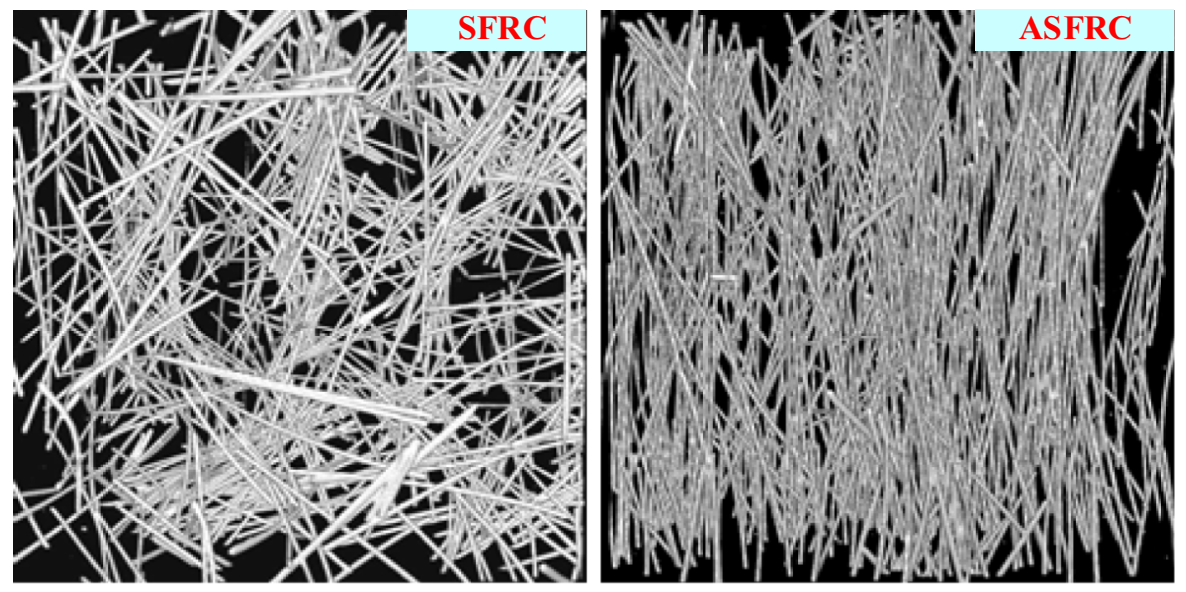

Fig. 3 Orientation of fibres in specimens determined by X-ray CT scanning

\subsection{The effect of fibre orientation on the uniaxial tensile stress-strain relationship}

The tensile stress-strain curves of ASFRC are significantly higher than that of ordinary SFRC (as shown in Fig. 4, the segment from the end of the elastic part to the peak load point of the curve is defined as the hardening branch, and that after the peak load point is defined as the softening branch). This suggests that the ASFRC composite is an improvement over the traditional SFRC composite, certainly in terms of tensile behavior and ductility. Although the tensile strength is improved, the hardening phase is not pronounced if the matrix strength is relatively small (as shown in Fig. 4a), while the tensile strength and ductility of ASFRC specimen with $w / c=0.36$ and 0.32 significantly exceed those of SFRC (as shown in Figs. $4 \mathrm{~b}, \mathrm{c}$ ). The matrix has not cracked in the initial stage of tension (elastic stage); the effect of the fibre orientation at this stage therefore is small (see Fig. 4); although as expected the SFRC specimens cracked at a lower stress than the ASFRC specimens. After matrix cracking, the stress-strain curves of ASFRC specimens are characterized by a longer hardening branch under uniaxial tension, especially with a higher matrix strength, as shown in Figs. 4b, c. Normally, three main phases can be identified in the stress-strain curves: elastic, hardening and softening. A new cementitious composite with a higher tensile performance and ductility can be designed through the alignment of the steel fibres by using a magnetic field.

The tensile strength $f_{\text {Utu }}$ and ultimate strain $\varepsilon_{\text {Utu }}$ (corresponding to the tensile strength $f_{\mathrm{Utu}}$ ) were significantly enhanced by the alignment of the steel fibres. The uniaxial tensile results for each series of SFRC and ASFRC specimens are given in Table 2 (the "ASFRC0.8-1" denotes the No. 1 ASFRC specimen with $V_{\mathrm{f}}=0.8 \%$ ), where it can clearly be seen that at increasing matrix strength, the improvement of $f_{\mathrm{Utu}}$ for the ASFRC specimens is higher than that of the SFRC specimens. Compared with the SFRC specimens, the average tensile strength of ASFRC specimens 


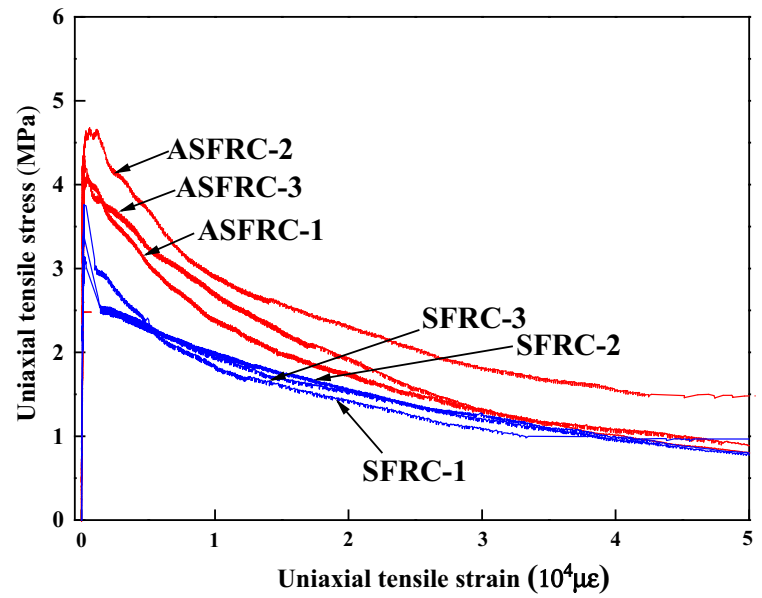

(a)

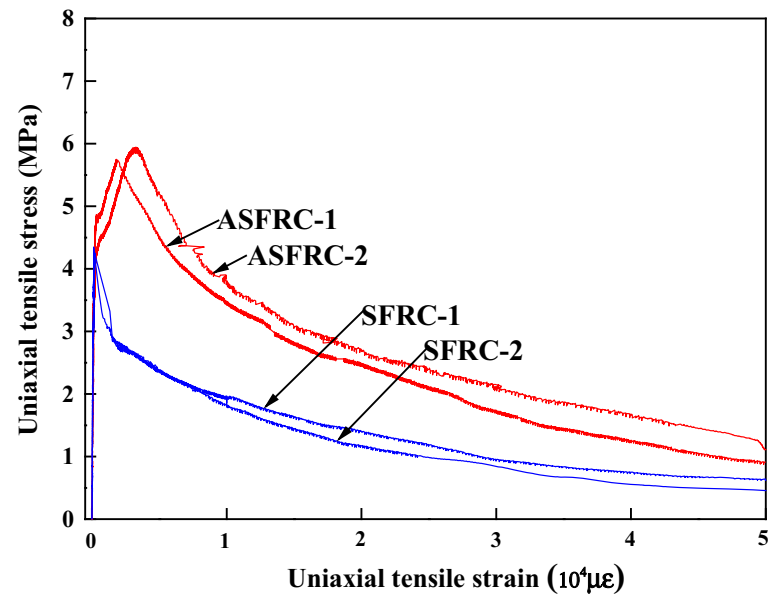

(b)

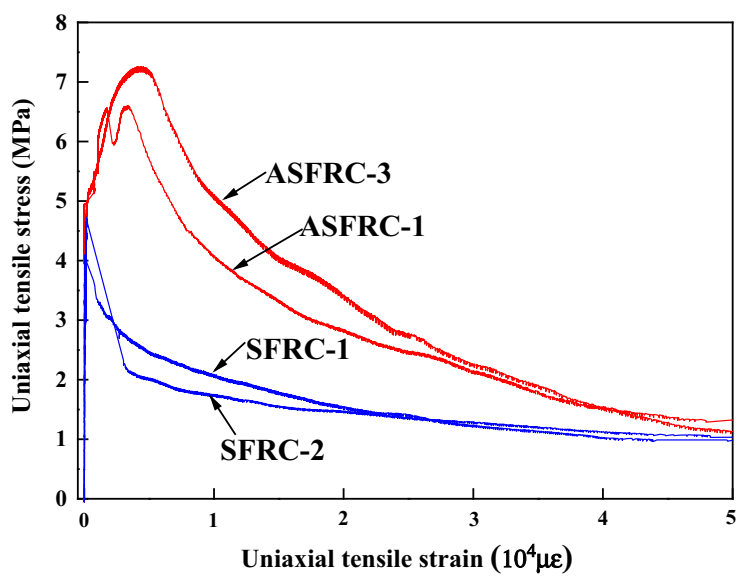

(c)

Fig. 4 Uniaxial tensile stress-strain curves of ASFRC specimens with $V_{\mathrm{f}}=2 \%$ : a $w / c=0.42$, b $w / c=0.36, \mathbf{c} w / c=0.32$

increases by $26.96 \%, 44.09 \%$ and $57.14 \%$ corresponding to $w / c$-ratios of $0.42,0.36$ and 0.32 , respectively. Obviously, with the increase in matrix strength, the reinforcement efficiency of fibres with regard to $f_{\mathrm{Utu}}$ becomes higher. This characteristic is due to fact that the enhancement of the steel fibres highly depends on the mechanical interaction of the bond, friction and mechanical interlocking between the fibre and matrix [27]; the bond between fibres and matrix increases at increasing strength of the matrix. As described in Sect. 3, the change in the orientation of steel fibers causes the difference in the number of fibers in the different sections, more steel fibres crossed the cracked section of ASFRC specimens compared to SFRC specimens. In addition, the orientation of fibres influences the damage of the matrix. As shown in
Fig. 5 and based on acoustic emission signal analysis [40], the matrix of SFRC specimens with random fibres is damaged more severely than that of ASFRC specimens. The total resistance force is greater in the ASFRC specimen compared to SFRC specimens with the same fibre volume fraction.

The reinforcement due to the action of the steel fibres on the toughness behavior can be determined from the ultimate strain $\varepsilon_{\mathrm{Utu}}$. As shown in Table 2, the mean values of $\varepsilon_{U t u}$ were similar for the SFRC specimens with different $w / c$-ratios. However, $\varepsilon_{\mathrm{Utu}}$ of the ASFRC specimens varied greatly for the different $w / c$-ratios compared to the SFRC specimens. The increase in $\varepsilon_{\mathrm{Utu}}$ for the ASFRC specimens is more pronounced compared to the matrix strength increase. Due to the alignment of the steel fibres, the toughness 


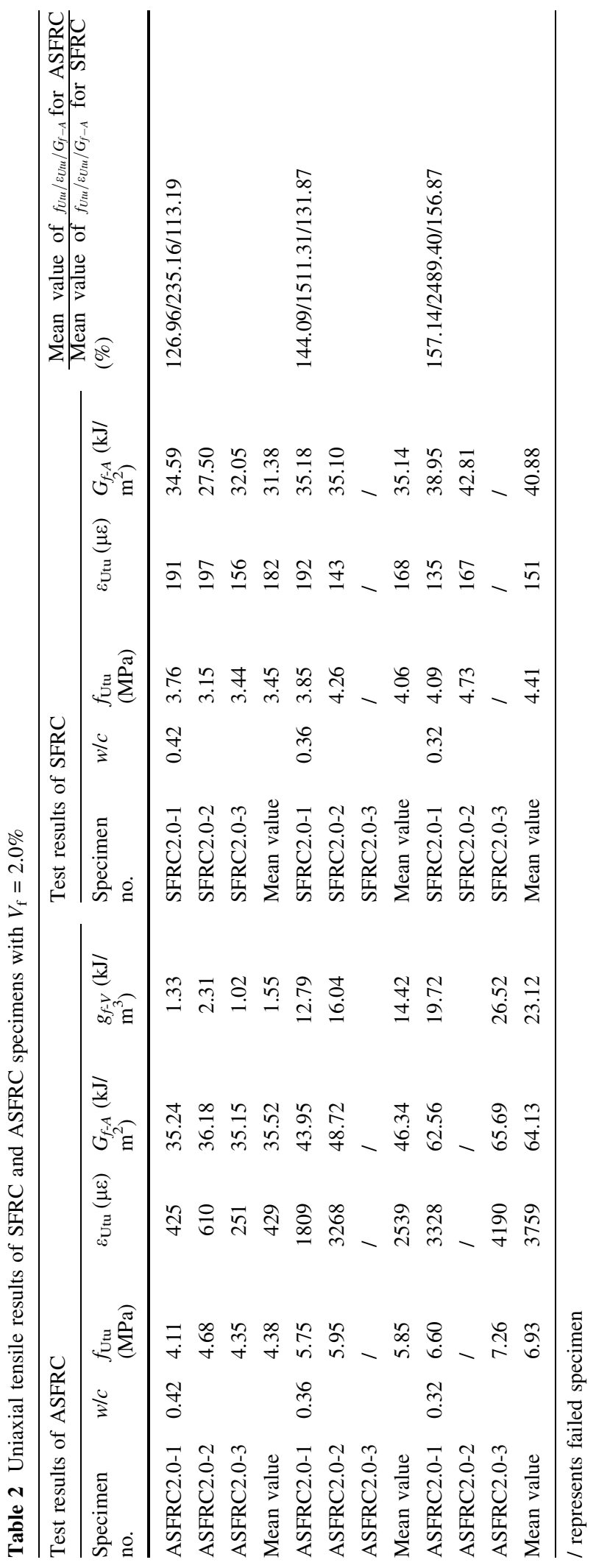


Fig. 5 Change in the embedded length of a steel fiber in SFRC and ASFRC [40]

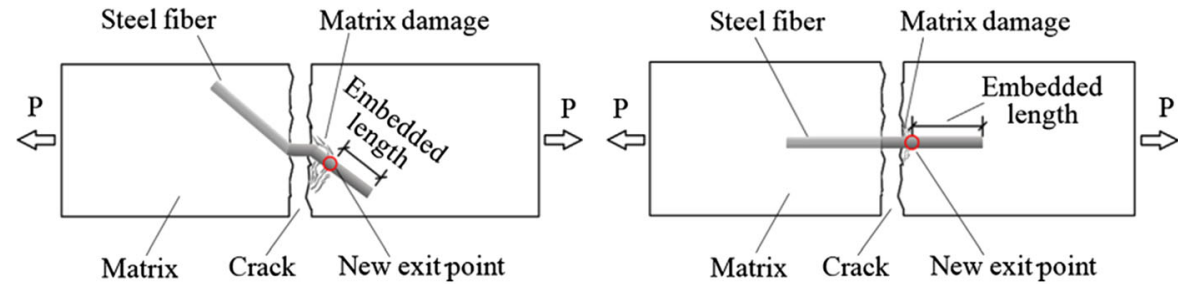

(a) SFRC

(b) ASFRC of the composites was significantly enhanced (strainhardening occurred).

\subsection{The effects of fibre orientation on the fracture properties}

\subsubsection{Energy dissipation}

Improving energy dissipation (i.e., impact resistance and ductility) is an important aspect for the behavior of a structure [41-43]. Strain-hardening and strain-softening behaviors are characterized by the energy dissipated per unit volume $g_{f-V}$ (in the stage of strain-hardening) and energy dissipated per crack surface area $G_{f-A}$ (in the post-peak stage/strainsoftening) [22, 44], respectively. The $G_{f-A}$ of the cementitious materials can be increased significantly by aligning the steel fibres, as shown in Table 2 (the integral range for $G_{f-A}$ was from $\varepsilon_{\text {Utu }}$ to $11 \%$. Also note in Fig. 4 that there was no obvious hardening branch in the curves of the SFRC specimens; the $g_{f-V}$ of the SFRC could not be calculated). Compared with the SFRC specimens, the $G_{f-A}$ of the ASFRC specimens $\left(V_{\mathrm{f}}=2.0 \%\right.$ and $\left.w / c=0.32\right)$ increased by $56.87 \%$, which is approximately equal to the increase in magnitude of $f_{\mathrm{Utu}}(57.14 \%)$. Obviously, with the increase in matrix strength, the ascending amplitude of $G_{f-A}$ for the ASFRC specimens is higher than that of the SFRC specimens; this can be seen in Fig. 6. In this study, where the matrix of the SFRC and ASFRC specimens is without aggregates, the properties of the interface between the fibre and the matrix was significantly affected by the $w / c$. Two $w / c$-ratios were investigated (0.32 and 0.42) and the matrix with the lower $w / c$ had a higher matrix strength, a stronger bond between fibres and matrix, and stronger energy dissipation during pullout of the fibres in the softening stage-the improvement in $G_{f-A}$ at the low $w / c$ of 0.32 is significantly higher than that of the matrix with a $w /$ $c$ of 0.42 .

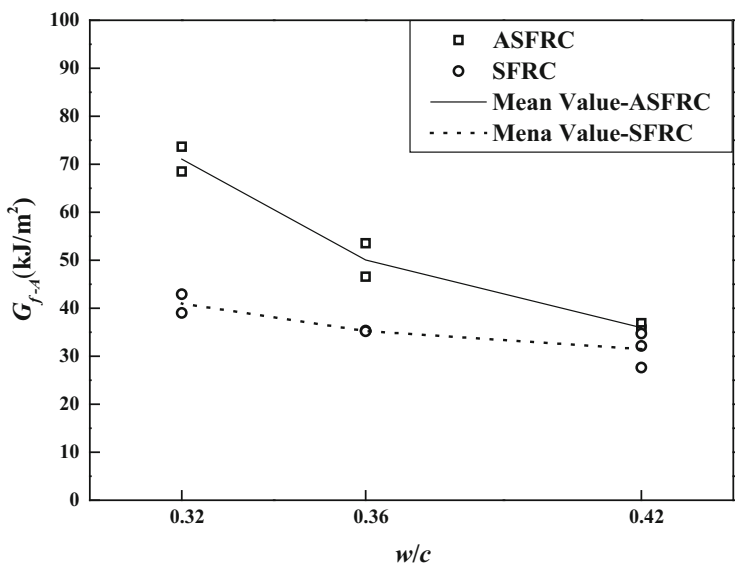

Fig. 6 The effect of $w / c$ on the $G_{f-A}$ of SFRC and ASFRC specimens with $V_{\mathrm{f}}=2.0 \%$

\subsubsection{Multiple cracking behavior of ASFRC as determined by the DIC method}

The strain fields of ASFRC specimens at different moments during testing are presented in Fig. $7\left(P_{\max }\right.$ represents the peak load, “ $\uparrow$ " represents loading [i.e., ascending branch of stress-strain curve] and " $\downarrow$ " corresponds to measurements of the descending branch). For SFRC specimens (the results can be seen in Fig. S4 in the Supplementary Material), a single micro-crack gradually evolved into a macro-crack with an increase in the tensile load. After $P_{\max }$ was surpassed, due to the debonding and pull-out of the fibres, the rapid macro-crack propagation led to the complete failure of the specimens. In comparison with the ASFRC specimens, the whole process of single crack development is faster in SFRC specimens, and the tensile strain of the specimen is smaller. As shown in Fig. 7, the first micro-crack appears between 70 and $80 \%$ of $P_{\max }$ for ASFRC specimens with $w / c=0.32$ and $V_{\mathrm{f}}=2.0 \%$. Then, multiple cracks are formed in the matrix as the load was increased to about $90 \%$ of $P_{\max }$ (during the hardening stage). In the softening 


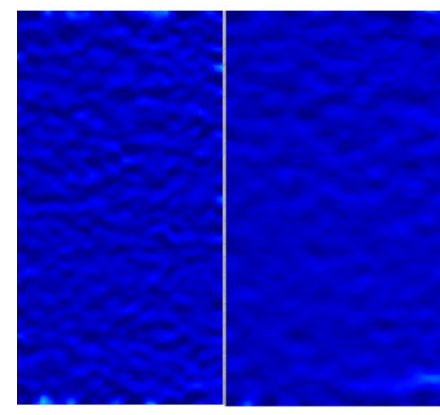

(i) $60 \% P_{\max }(\uparrow)$

(ii) $70 \% P_{\max }(\uparrow)$

(iii) $80 \% P_{\max }(\uparrow)$

(iv) $90 \% P_{\max }(\uparrow)$

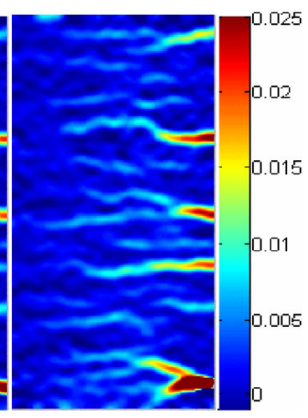

(v) $P_{\max }$

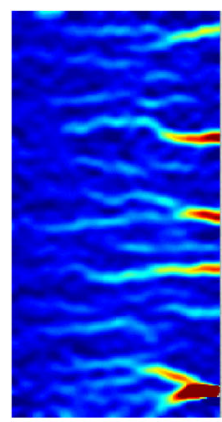

(vi) $90 \% P_{\max }(\downarrow)$

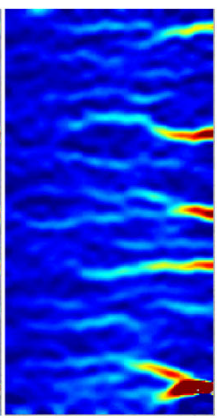

(vii) $80 \% P_{\max }(\downarrow)$ (viii) $70 \% P_{\max }(\downarrow)$

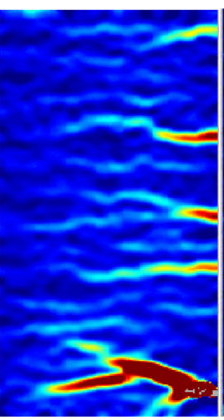

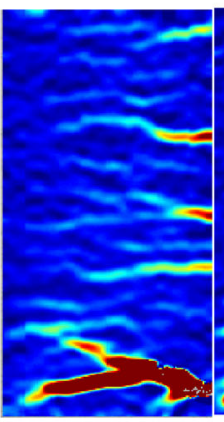

(ix) $60 \% P_{\max }(\downarrow)$

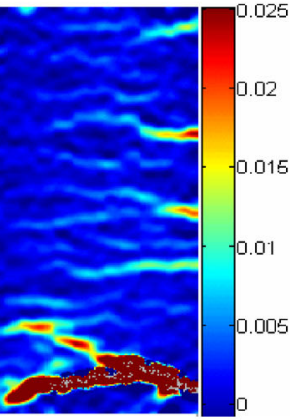

(x) $40 \% P_{\max }(\downarrow)$

Fig. 7 Strain field of ASFRC specimen $\left(w / c=0.32, V_{\mathrm{f}}=2.0 \%\right)$ at different moments of loading under uniaxial tension

stage, with the development of the macro cracks, the specimen gradually loses its bearing capacity. The multiple cracking behavior for the ASFRC specimens with a lower fibre content was not observed during tension.

The orientation number of the steel fibres in the ASFRC specimens $\left(w / c=0.32, V_{\mathrm{f}}=2.0 \%\right)$ is around 0.90 , as determined by the $\mathrm{X}-\mathrm{CT}$ images analysis. Obviously, the number of fibres within the cracked section at complete failure of the ASFRC specimens $\left(N_{f-A}\right)$ is higher than that for the SFRC specimens $\left(N_{f-}\right.$ ${ }_{R}$ ) due to higher fibre orientation number (the average $N_{f-R}$ is 495 for the SFRC specimens, the average $N_{f-A}$ is 612 for the ASFRC specimens [ $V_{\mathrm{f}}=2.0 \%$ ], which is a $23.6 \%$ increase). This will lead to higher and additional stresses being transferred to the surrounding matrix. If the additional tensile stresses transferred to the surrounding matrix exceed the cracking strength of the matrix, then further multiple cracks are formed. As more cracks are generated, the resistance of the steel fibres bridging these cracks contributes to the postcracking toughness of the ASFRC composites which far exceeds the tensile capacity found in composites failing with the opening of only a single crack. Hence, the $\varepsilon_{\text {Utu }}$ of ASFRC is significantly higher than that of SFRC. It is worth mentioning that the micro-cracks were only revealed by the DIC equipment (they could not be identified from a visual inspection).

The formation of multiple cracks of SFRC specimens was often accompanied by strain-hardening (i.e., good ductility performance), especially for UHPFRC material, where the uniaxial tensile test results of UHPFRC with $2.0 \%$ hybrid fibres (1.0\% macro-fibres and $1.0 \%$ micro-fibres) also produced multiple cracking [33]. The multiple cracking also was observed during the execution of uniaxial tensile test with highperformance fibre reinforced cementitious composites (HPFRCC) with 2\% Torex fibres [36]. Similar results can be found in the uniaxial tensile tests for SFRC with large hooked-end fibre contents $\left(V_{\mathrm{f}}=5.0 \%\right)$ [45] and for UHPFRC with over $2 \%$ of fibres [22, 32, 34, 35]. Generally, these specimens with multiple cracks also show superior tensile behavior and post-cracking ductility [46]. Compared with SFRC, multiple cracks 
can be formed in ASFRC at a lower fibre content, and the post-cracking toughness and tensile behavior are significantly improved.

\subsection{Discussion}

Results of ASFRC uniaxial tensile tests with $w /$ $c=0.36$ and $V_{\mathrm{f}}=1.2 \%$ are shown in Fig. 8 (ASFRC specimens with $V_{\mathrm{f}}=0.8 \%, 1.6 \%$ and energy dissipation $\left(G_{f-A}\right)$ with different $V_{\mathrm{f}}$ also can be seen in Fig. S5 and Fig. S6 in the Supplementary Material, respectively). From Fig. S5(a) in the Supplementary Material, it can be seen that even when the fibres are aligned, if the fibre content is low $\left(V_{\mathrm{f}}=0.8 \%\right)$, there will be insufficient fibres in the cross-section of the cracks to influence the toughness of the ASFRC specimen. As $V_{\mathrm{f}}$ increases, strain-hardening becomes more significant. However, there is no similar strainhardening branch in the curve for the SFRC specimens $(w / c=0.36)$ with $V_{\mathrm{f}}=2.0 \%$ (see Fig. 8), which is further evidence that the post-cracking tensile behavior and toughness can be significantly enhanced by the alignment of the steel fibres, especially for specimens at a relatively high fibre content.

From the tests results of the ASFRC specimens ( $w /$ $c=0.36)$ with different $V_{\mathrm{f}}$ and those of the SFRC specimens $(w / c=0.36)$ with $V_{\mathrm{f}}=2.0 \%$ (as shown in Fig. S5 and Fig. 8), it can be seen that the uniaxial tensile strength of the ASFRC specimens with $V_{\mathrm{f}}$ $=1.2 \%$ is $4.37 \mathrm{MPa}$; this is slightly higher than the $f_{\mathrm{Utu}}$ of the SFRC specimens $(w / c=0.36)$ with $V_{\mathrm{f}}$

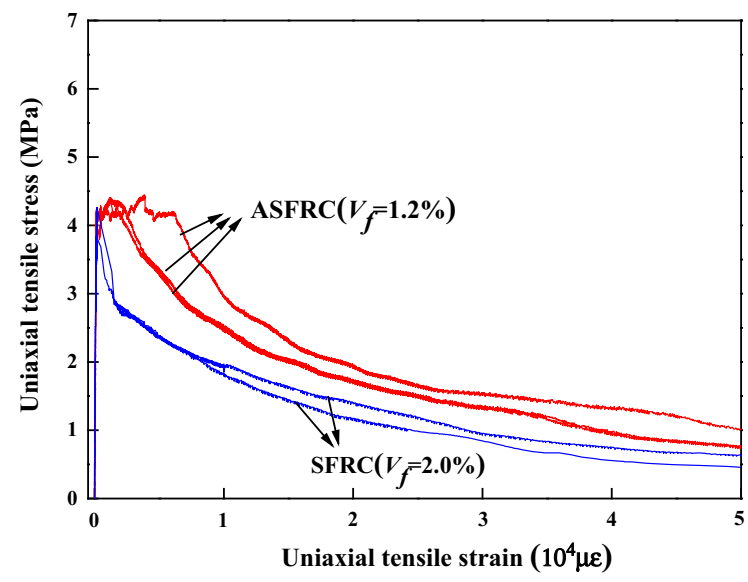

Fig. 8 The comparison of uniaxial tensile stress-strain curves between SFRC specimens $\left(w / c=0.36, V_{\mathrm{f}}=2.0 \%\right)$ and ASFRC specimens $\left(w / c=0.36, V_{\mathrm{f}}=1.2 \%\right)$
$=2.0 \%(4.06 \mathrm{MPa})$. Accordingly, SFRC specimens with $V_{\mathrm{f}}=2.0 \%$ can be replaced by ASFRC specimens with $V_{\mathrm{f}}=1.2 \%$, at least $40 \%$ saving in steel fibres is possible if only considering the orientation of the aligned fibres. Moreover, the energy dissipation capacity of the ASFRC specimens far exceeds that of the SFRC specimens (see Fig. 8), which is a significant practical benefit. It should be noted that the performance of ASFRC in other directions is less than that of SFRC.

\section{Conclusions}

The ASFRC specimens were prepared using a uniform magnetic field formed from energized coils during casting, and the effect on the alignment of steel fibres was examined using an X-ray CT system. The influence of fibre orientation on the strain-hardening and fracture properties of SFRC specimens were investigated. The process of multiple crack propagation in the ASFRC specimens subjected to uniaxial tension was assessed using the DIC method. Based on the analysis of the test results, the main conclusions of this study are as follows:

1. Compared with SFRC, ASFRC performs better in terms of uniaxial tensile strength $\left(f_{\mathrm{Utu}}\right)$, postcracking toughness and energy dissipation $\left(G_{f-A}\right)$. With an increase in the matrix strength and fibre content, this improvement becomes more obvious. Based on these results, the alignment of steel fibres using a magnetic field technology appears to be an effective method to produce high performance cementitious composite materials.

2. The uniaxial tensile behavior of ASFRC specimens $(w / c=0.36)$ with $V_{\mathrm{f}}=1.2 \%$ is equivalent to that of SFRC specimens $(w / c=0.36)$ with $V_{\mathrm{f}}$ $=2.0 \%$; this results in at least $40 \%$ saving in fibre content if only considering the orientation of aligned fibre. Moreover, the ASFRC specimens exhibit strain-hardening after first crack formation during the uniaxial tension tests (for $V_{\mathrm{f}}>0.8 \%$ ) and an significant improvement in the post-peak ductile behavior is obtained (again this improvement increases with an increase in fibre content).

3. Compared with ordinary SFRC with dispersed fibres, the multiple cracks for ASFRC $(w / c$ $=0.32)$ can be formed at a low fibre content $\left(V_{\mathrm{f}}\right.$ 
$=2.0 \%$ ) due to the alignment of fibres perpendicular to the crack surface, the post-cracking toughness and tensile behavior is significantly improved for cementitious materials. The initial cracking load of the ASFRC specimens under tension is around $70 \% P_{\max }$; multiple cracking takes place in the matrix up until the tensile load of around $90 \%$ $P_{\max }$.

Acknowledgements The work presented in the paper was supported by the National Natural Science Foundation of China (Nos. 51578208, 51878239, 51779069 and 5171101996).

\section{Compliance with ethical standards}

Conflict of interest The authors declare that they have no conflict of interest.

Open Access This article is licensed under a Creative Commons Attribution 4.0 International License, which permits use, sharing, adaptation, distribution and reproduction in any medium or format, as long as you give appropriate credit to the original author(s) and the source, provide a link to the Creative Commons licence, and indicate if changes were made. The images or other third party material in this article are included in the article's Creative Commons licence, unless indicated otherwise in a credit line to the material. If material is not included in the article's Creative Commons licence and your intended use is not permitted by statutory regulation or exceeds the permitted use, you will need to obtain permission directly from the copyright holder. To view a copy of this licence, visit http://creativecommons.org/licenses/by/4.0/.

\section{References}

1. Mangat P (1976) Tensile strength of steel fiber reinforced concrete. Cem Concr Res 6(2):245-252

2. Caggiano A, Cremona M, Faella C (2012) Fracture behavior of concrete beams reinforced with mixed long/short steel fibers. Constr Build Mater 37(3):832-840

3. Jin L, Zhang R, Tian Y, Dou G, Du X (2018) Experimental investigation on static and dynamic mechanical properties of steel fiber reinforced ultra-high-strength concretes. Constr Build Mater 178:102-111

4. Bischoff PH (2003) Tension stiffening and cracking of steel fiber-reinforced concrete. J Mater Civ Eng 15(2):174-182

5. Xu Z, Hao H, Li HN (2012) Experimental study of dynamic compressive properties of fibre reinforced concrete material with different fibres. Mater Des 33(1):42-55

6. Germano F, Tiberti G, Plizzari G (2015) Post-peak fatigue performance of steel fiber reinforced concrete under flexure. Mater Struct 49(10):4229-4245

7. Tran TK, Kim DJ (2013) Investigating direct tensile behavior of high performance fiber reinforced cementitious composites at high strain rates. Cem Concr Res 50:62-73
8. Sun X, Zhao K, Li Y et al (2018) A study of strain-rate effect and fiber reinforcement effect on dynamic behavior of steel fiber-reinforced concrete. Constr Build Mater 158:657-669

9. Soroushian P, Lee C-D (1990) Distribution and orientation of fibers in steel fiber reinforced concrete. Mater $\mathbf{J}$ 87(5):433-439

10. Fu SY, Lauke B (1996) Effects of fiber length and fiber orientation distributions on the tensile strength of shortfiber-reinforced polymers. Compos Sci Technol 56(10):1179-1190

11. Brandt AM (1985) On the optimal direction of short metal fibres in brittle matrix composites. J Mater Sci 20(11):3831-3841

12. de Oliveira FL (2010) Design-oriented constitutive model for steel fiber reinforced concrete. Universitat Politècnica de Catalunya, Barcelona

13. Segura-Castillo L, Cavalaro SHP, Goodier C et al (2018) Fibre distribution and tensile response anisotropy in sprayed fibre reinforced concrete. Mater Struct 51(1):29

14. Rotondo PL, Weiner KH (1986) Aligned steel fibers in concrete poles. Concr Int 8(12):22-27

15. Xu XM (1993) A new type of steel fiber reinforced concrete. Arch Technol 20(4):240-241

16. Duque LFM, Graybeal B (2017) Fiber orientation distribution and tensile mechanical response in UHPFRC. Mater Struct 50:55

17. Abrishambaf A, Barros JA, Cunha VM, Cunha F (2012) Assessment of fibre orientation and distribution in steel fibre reinforced self-compacting concrete panels. In: 8th RILEM international symposium on fibre reinforced concrete: challenges and opportunities, pp 1-12

18. Abrishambaf A, Barros JAO, Cunha VMCF (2013) Relation between fibre distribution and post-cracking behaviour in steel fibre reinforced self-compacting concrete panels. Cem Concr Res 51:57-66

19. Nunes S, Pimentel M, Carvalho A (2016) Non-destructive assessment of fibre content and orientation in UHPFRC layers based on a magnetic method. Cem Concr Compos 72:66-79

20. Nunes S, Pimentel M, Carvalho A (2017) Estimation of the tensile strength of UHPFRC layers based on non-destructive assessment of the fibre content and orientation. Cem Concr Compos 83:222-238

21. Pimentel M, Nunes S (2016) Determination of the tensile response of UHPFRC layers using a non-destructive method for assessing the fibre content and orientation. In: Saouma V, Bolander J, Landis E (eds) 9th International conference on fracture mechanics of concrete and concrete structures, FraMCoS-9, California, USA

22. Abrishambaf A, Pimentel M, Nunes S (2017) Influence of fibre orientation on the tensile correspond of ultra-high performance fibre reinforced cementitious composites. Cem Concr Res 97:28-40

23. Michels J, Gams M (2016) Preliminary study on the influence of fibre orientation in fibre reinforced mortars. Gradevinar 68(8):645-655

24. Mu R, Li H, Qing L, Lin J, Zhao Q (2017) Aligning steel fibers in cement mortar using electro-magnetic field. Constr Build Mater 131:309-316 
25. Mu R, Wang Z, Wang X, Qing L, Li H (2018) Experimental study on shear properties of aligned steel fiber reinforced cement-based composites. Constr Build Mater 184:27-33

26. Wijffels MJH, Wolfs RJM, Suiker ASJ, Salet TAM (2017) Magnetic orientation of steel fibres in self-compacting concrete beams: effect on failure behaviour. Cem Concr Compos 80:342-355

27. Gopalaratnam VS, Shah SP (1987) Tensile failure of steel fiber-reinforced mortar. J Eng Mech 113(5):635-652

28. Yoo D-Y, Yoon Y-S, Banthia N (2015) Flexural response of steel-fiber-reinforced concrete beams: effects of strength, fiber content, and strain-rate. Cem Concr Compos 64:84-92

29. Olivito RS, Zuccarello FA (2010) An experimental study on the tensile strength of steel fiber reinforced concrete. Compos B 41(3):246-255

30. Ding YN, Yan YC (2011) Experimental investigation on uniaxial tensile properties of steel fiber reinforced concrete. Appl Mech Mater 94:731-735

31. Hassan AMT, Jones SW, Mahmud GH (2012) Experimental test methods to determine the uniaxial tensile and compressive behaviour of ultra high performance fibre reinforced concrete (UHPFRC). Constr Build Mater 37:874-882

32. Fantilli AP, Mihashi H, Vallini P (2009) Multiple cracking and strain hardening in fiber-reinforced concrete under uniaxial tension. Cem Concr Res 39(12):1217-1229

33. Park SH, Kim DJ, Ryu GS, Koh KT (2012) Tensile behavior of ultra high performance hybrid fiber reinforced concrete. Cem Concr Compos 34(2):172-184

34. Graybeal BA, Baby F (2013) Development of direct tension test method for ultra-high-performance fibre-reinforced concrete. ACI Mater J 110(2):177-186

35. Pyo S, Wille K, El-Tawil S, Naaman AE (2015) Strain rate dependent properties of ultra high performance fiber reinforced concrete (UHP-FRC) under tension. Cem Concr Compos 56:15-24

36. Naaman AE (2003) Engineered steel fibers with optimal properties for reinforcement of cement composites. J Adv Concr Technol 1(3):241-252

37. Dupont D, Vandewalle L (2005) Distribution of steel fibres in rectangular sections. Cem Concr Compos 27(3):391-398
38. Stroeven P, Hu J (2006) Effectiveness near boundaries of fibre reinforcement in concrete. Mater Struct 39(10): 1001-1013

39. Hamrat M, Boulekbache B, Chemrouk M, Amziane S (2016) Flexural cracking behavior of normal strength, high strength and high strength fiber concrete beams, using digital image correlation technique. Constr Build Mater 106:678-692

40. Mu R, Xing P, Yu J, Wei L, Zhao Q, Qing L, Zhou J, Tian W, Gao S, Zhao X, Wang X (2019) Investigation on reinforcement of aligned steel fiber on flexural behavior of cement-based composites using acoustic emission signal analysis. Constr Build Mater 201:42-50

41. Maalej M, Quek ST, Zhang J (2005) Behavior of hybridfiber engineered cementitious composites subjected to dynamic tensile loading and projectile impact. J Mater Civ Eng 17(2):143-152

42. Richardson A, Coventry K (2015) Dovetailed and hybrid synthetic fibre concrete-impact, toughness and strength performance. Constr Build Mater 78:439-449

43. Tran NT, Tran TK, Jeon JK, Park JK, Kim DJ (2016) Fracture energy of ultra-high-performance fiber-reinforced concrete at high strain rates. Cem Concr Res 79:169-184

44. Wille K, El-Tawil S, Naaman AE (2014) Properties of strain hardening ultra high performance fiber reinforced concrete (UHP-FRC) under direct tensile loading. Cem Concr Compos 48:53-66

45. Rinaldi Z, Grimaldi A (2006) Influence of high performance fiber reinforced concrete on the ductility of beam elements. In: International Rilem workshop on high performance fiber reinforced cementitious composites (HPFRCC) in structural applications. Rilem Publications SARL, Bagneux

46. Wille K, Kim DJ, Naaman AE (2011) Strain-hardening UHP-FRC with low fiber contents. Mater Struct 44(3):583-598

Publisher's Note Springer Nature remains neutral with regard to jurisdictional claims in published maps and institutional affiliations. 